\title{
Obezitenin Belirlenmesinde Kullanılan Beden Kitle İndeksi, Bel Çevresi, Bel- Kalça Oranı Metotlarının Karşılaştırılması
}

\author{
Hülya TAŞLI \\ Kırşehir Ahi Evran Üniversitesi, Fen Edebiyat Fakültesi \\ hulyatasli@outlook.com \\ ORCID ID: 0000-0003-2117-4408 \\ Seçil SAĞIR \\ Kırşehir Ahi Evran Üniversitesi, Fen Edebiyat Fakültesi \\ secilgung@gmail.com \\ ORCID ID: 0000-0001-9291-8406
}

Araştırma Makalesi

Geliş Tarihi: 05.05.2020

Revize Tarihi: 11.03.2021

DOI: $10.31592 /$ aeusbed.732550

Kabul Tarihi: 11.03.2021

\section{Atıf Bilgisi}

Taşlı, H. ve Sağır, S. (2021). Obezitenin belirlenmesinde kullanılan beden kitle indeksi, bel çevresi, bel-kalça oranı metotlarının karşılaştırılması. Ahi Evran Üniversitesi Sosyal Bilimler Enstitüsü Dergisi, 7(1), 138-150.

ÖZ

Obezite teşhisinde kullanılan yöntemlerin birbirinden farklı sonuçlar ortaya koyması obezitenin teşhisinde hangi yöntemin kullanılacağına ilişkin tartışmalara neden olmaktadır. Bu araştırmada obezite teşhisinde kullanılan beden kitle indeksi, bel çevresi, bel kalça oranı metotlarının kendi aralarında karşılaştırılması amaçlanmaktadır. 201 kadın ve 205 erkek öğrenciden boy uzunluğu, ağırlık, bel çevresi, kalça çevresi ölçüleri alınmıştır. Beden kitle indeksine göre kadın bireylerin obezite oranı \%4.5, erkeklerin \%6.4'tür. Bel çevresine göre kadın bireylerin obezite oranı \%3, erkeklerin \%2.4'tür. Bel kalça oranına göre kadın bireylerin obezite oranı \%1, erkeklerin \%4.4'tür. Elde edilen bulgular istatistiksel olarak karşılaştırılmış ve buna göre cinsiyetler arasında obezite oranları açısından anlamlı bir farka rastlanılmıştır $(\mathrm{p}<0.05)$. Üç yöntemin istatistiksel olarak karşılaştırılması sonucunda aralarında anlamlı bir fark bulunmuştur $(p<0.05)$. Elde edilen bulgular sonucunda obezitenin teşhisinde en az iki yöntemin değerlendirilmesi önerilmektedir. Bel kalça oranının kadınlarda obeziteyi teşhis etmede yetersiz olduğu görülmüştür. Erkeklerde ise yalnızca abdominal obezite oranlarını ortaya koyduğu, genel obezite oranı hakkında yanıltıcı bilgiler verdiği görülmektedir. $\mathrm{Bu}$ nedenle beden kitle indeksi ile elde edilen veri mutlaka bel çevresi ölçümü ile desteklenmelidir. Tek bir yöntemden yola çıkarak bireylere obezite teşhisi koymanın doğru sonuçlar vermeyeceği düşünülmektedir.

Anahtar Kelimeler: Beden kitle indeksi, bel çevresi, bel kalça oranı, obezite.

\section{Comparison of the Methods of Body Mass Index, Waist Circumference, Waist-Hip Ratio Used in the Determination of Obesity}

\begin{abstract}
The fact that the methods used in the diagnosis of obesity have different results cause controversy about which method to use in the diagnosis of obesity. In this study, it is aimed to compare the body mass index, waist circumference, waist hip ratio methods used in the diagnosis of obesity among themselves. Height, weight, waist circumference, hip circumference measurements were taken from 201 female and 205 male students. Obesity rate of female individuals is $4.5 \%$ and $6.4 \%$ of men according to body mass index. According to waist circumference, obesity rate of female individuals is $3 \%$, and male is $2.4 \%$. Obesity rate of female individuals is $1 \%$ and $4.4 \%$ of men according to waist-to-hip ratio. The findings were compared statistically and according to this, a significant difference was found between the sexes in terms of obesity rates $(\mathrm{p}<0.05)$. As a result of statistical comparison of the three methods, a significant difference was found between them $(p<0.05)$. As a result of the findings, it is recommended to evaluate at least two methods in the diagnosis of obesity. Waist hip ratio was found to be insufficient to diagnose obesity in women. In men, waist hip ratio is seen that only shows the rates of abdominal obesity and gives misleading information about the general obesity rate. For this reason, the data obtained with the body mass index must be supported by waist circumference measurement. It is thought that diagnosing individuals with obesity will not yield accurate results based on a single method.
\end{abstract}

Keywords: Body mass index, waist circumference, waist to hip ratio, obesity.

\section{Giriş}

Obezite halk arasında fazla şişmanlık olarak bilinen, temel olarak vücudun harcadığı kalori miktarının, aldığı kaloriden az olması sonucu fazla kalorinin vücutta yağ olarak depolanmasıyla ortaya 
çıkan, beraberinde birçok sağlık problemine ve bunlara bağlı olarak ölümlere neden olabilen metabolik bir hastalıktır (Berghöfer, 2008; Ünal, 2004). Obezite bireylerin koroner arter hastalığı, hipertansiyon, tip II diyabet, obstrüktif akciğer hastalığı, osteoartrit ve bazı kanser türlerine yakalanma riskini artıran, yaşam süresini önemli ölçüde azaltan bir sağlık sorunudur. Araştırmalar göstermektedir ki hipertansiyon, hiperlipidemi ve tip 2 diyabet prevelans 1 obez bireylerde 2-3 kat daha fazla görülmektedir (Heyward ve Stolarczyk, 1996). Dünya Sağlık Örgütü her yıl obeziteye bağlı hastalıklar nedeniyle ortalama 3 milyon insanın hayatını kaybettiğini bildirmektedir. Obezite bu denli zarar verici ve tahrip edici etkisine rağmen en çok ihmal edilen halk sağlığı problemlerinin arasında yer almaktadır. Dünya Sağlık Örgütü (WHO) ancak 1997'de obezitenin etkilerini küresel bir sorun olarak kabul etmiştir (Turan, 2017). Yaş, cinsiyet, hareketsiz yaşam tarzı, yanlış beslenme, alkol ve sigara kullanımı, hormonal ve metabolik faktörler gibi pek çok etmen obeziteye sebep olabilmektedir. İnsan vücudunda obezitenin negatif etkilerinden etkilenmeyen organizma neredeyse bulunmamaktadır (Sturm, 2002). Beden kitle indeksi genel olarak obezite ölçümünde ilk adım ve en ideal yöntemdir ancak kaba bir rehber olarak düşünülmektedir. Çünkü farklı kişilerdeki yağ oranları aynı şişmanlık düzeyine denk gelmez. WHO beden kitle indeksi değerinin $25^{\prime}$ 'den fazla olmasını şişman, 30'dan fazla olmasını obez olarak değerlendirsede popülasyonlardaki kronik hastalık riskinin beden kitle indeksi değerinin 21'den sonra artış gösterdiğine dair kanıtlar ortaya çıkmaktadır. Bir zamanlar yalnızca yüksek gelirli ülkelerin bir sorunu olarak kabul edilse de günümüzde fazla kiloluluk ve obezite düşük ve orta gelirli ülkelerde, özellikle kentsel bölgelerde artış göstermektedir. Obezitenin bu denli artışının en temel sebepleri; ulaşım, üretim, tarım sektörü ve eğlence sektörü bunlarla birlikte gelişen teknoloji, beslenme alışkanlıkların hızla değişmesi olarak sayılabilir. Özellikle fast food gibi sağlıksız besinler başta olmak üzere rafine karbonhidratlardan zengin, aşırı yağlı, bitkisel lifler açısından oldukça fakir ve yoğun enerjili beslenme şekli bunlara bağlı olarak enerji alımının artması obeziteye neden olan en önemli faktörlerdendir (Bray, 2004; Sturm, 2002; Türkiye Endokrinoloji ve Metabolizma Derneği, 2018).

Obezitenin belirlenmesinde en temel yöntemlerden biri olan beden kitle indeksi WHO tarafindan da obezitenin belirlenmesinde ilk başvurulan yöntemdir. Ancak beden kitle indeksi (BKI) artan kas dokusunun ağırlığını, vücudun su tutması ve yağ dokusunun dağılımını hesaba katmaz. Benzer beden kitle indeksine sahip olan bireylerin özellikle karın yağ dokusu farklılık gösterebilir. Bu nedenle, bel çevresi ve bel kalça oranı (BKO) ölçümleri, hem klinik hem de araştırma ortamlarında düzenli olarak kullanılan ölçümlerle BKİye alternatif olarak görülmüştür (Akpınar, Bashan, Bozdemir ve Saatci, 2007).

Obezitenin saptanabilmesi için birçok yöntem bulunmaktadır. Ancak popülasyonlarüzerinde yapılan araştırmalarda birey sayılarının çokluğu kullanılacak yöntemlerin zamanve maliyet açısından minimum düzeye indirilmesini gerekli kılmıştır. Bu araştırma kapsamında Kırşehir Ahi Evran Üniversitesi'nde 406 birey üzerinden alınan antropometrik ölçümlerle beden kitle indeksi, bel çevresi ve bel kalça oranı metotlarıyla obezite prevelansının belirlenmesi, ayrıca obeziteyi belirlemede kullanılan yöntemlerin farklı sonuçlar ortaya koyması obezite teşhisinde hangi yöntemin tercih edileceği ile ilgili soru işaretleri meydana getirdiğinden kullanılan bu üç yöntemin de kendi aralarında karşılaştırılarak farklı ölçümlerin aynı popülasyon üzerinde nasıl sonuçlar ortaya verdiğini karşılaştırmak, araştırmanın temel amacını oluşturmaktadır.

\section{Yöntem}

Araştırmaya konu olan veriler Kırşehir Ahi Evran Üniversitesi Sosyal ve Beşeri Bilimler Bilimsel Araştırma ve Yayın Etiği Kurulunun 23.11.2018 tarihli toplantıs1 2018-23/07 sayılı kararı ile 2018-2019 yılları arasında Kırşehir Ahi Evran Üniversitesi'nin çeşitli fakültelerinde 18 yaşın üzerindeki 201 kadın ve 206 erkek bireyden oluşmaktadır. Araştırma gönüllülük esasına dayanmaktadır. Araştırmaya katılan her öğrenci gönüllü olduğunu beyan eden onam formunu imzalamıştır. Seçilen bireyler farklı sosyoekonomik düzeylerde ve farklı yaş gruplarındandır. Araştırma belli bir zamanda çok geniş bir sahada bilgi toplamayı hedefleyen tarama modelinden, kesit alma yaklaşımıyla gerçekleştirilmiştir. Obezitenin belirlenmesinde kullanılan beden kitle indeksi, bel çevresi, bel-kalça oranı gibi bazı antropometrik ölçümlerin aynı örneklem üzerinde nasıl farklılık 
gösterdiğini karşılaştırmayı amaçlayan bu araştırmanın bulguları seçilen örneklem ve araştırma alanı ile sınırlıdır. Örneklem olarak seçilen Kırşehir Ahi Evran Üniversitesi öğrencileri çok geniş bir kitle olduğu için örneklemde daraltılmaya gidilmiş 201 kadın ve 205 erkek öğrenciden oluşan 406 kişilik bir grup üzerinde araştırma yürütülmüştür.

\section{Verilerin Toplanması}

Araştırma kapsamında antropometri tekniği kullanılmıştır. Antropometri insan bedeninin nesnel özelliklerini, belirli ölçme yöntemleri ve ilkeleri ile boyutlandırıp yapı özelliklerine göre sınıflandıran bir tekniktir. Antropometri tekniği, insan vücudunun metrik boyutlarıyla ilgilenmektedir. Antropometri, klinik teşhislerde ve laboratuvarlarda, hem kentsel hem de kırsal koşullarda uygulanabilmektedir. Kullanılan aletler portatif ve alternatif araç gereçlere göre nispeten ucuzdur. Büyük örneklemlere rahatlıkla uygulanabilmesi, ucuz ve pratik olması gibi nedenler ile diğer yöntemlerden ayrılan antropometrik yöntemler tercih sebebidir (Bellisari ve Roche, 2005). Araştırma kapsamında bireylerde şişmanlık ve obezite düzeylerini belirlemek amacıyla alınan antropometrik ölçüler; kesitsel yöntemle (cross-sectional), Anthropometric Standardization Reference Manual (ASRM) ve Martin ve Saller'in (1957) öngördügü teknikler doğrultusunda, standartlara uygun olarak alınmış, ayrıca International Biological Programme (IBP)'in önerileri de göz önünde bulundurulmuştur (Martin, 1957; Tanner, Hiernaux ve Jarman, 1969; Weiner ve Lourie, 1969). Bireylerden ağırlık, boy uzunluğu, bel çevresi ölçümü ve kalça çevresi ölçümü alınmıştır. Aynı zamanda bu ölçümlerden beden kitle indeksi ve bel kalça oranı değerleri hesaplanmıştır. Ölçümlerden önce katılımcılar konu ile ilgili bilgilendirilmiş ve gönüllü onam formu imzalatılmıştır.

Boy uzunluğu: Boy uzunluğu iki kişi tarafindan Martin tipi antropometre ile ayakkabısız bir şekilde alınmıştır. Baş frankfurt düzleminde, omuzlar salık, topuklar bitişik ve ayak uçları arasında 45 derecelik bir açı olmasına dikkat edilmiştir. Araştırmacılardan birisi boy uzunluğunu ölçerken diğeri bireyin dik durmasını sağlamıştır. Horizantal kol bireyin başına fazla baskı yapmadan ölçüm alınmış ve milimetrik olarak kaydedilmiştir (Martin, 1957; Tanner vd., 1969; Weiner ve Lourie, 1969).

Ağırlık: Ağırlık ölçümü 100 gr.'a duyarlı dijital tartı ile alınmıştır. Bireyin üzerinde olabildiğince az kıyafet ve ayakkabısız olmasına dikkat edilmiştir. Ölçüm sırasında bireylerin herhangi bir yerden destek almamaları, hareket etmeden dik bir şekilde durmaları ve tartıya eşit bir şekilde basmalarısağlanmıştır (Martin, 1957; Tanner vd., 1969; Weiner ve Lourie, 1969).

Bel Çevresi: Bel çevresi ölçümü bireyin vücut şekline göre değişim göstermektedir. Zayıf bireylerde bel çevresi ölçümü belin en girintili olduğu noktadan, kilolu bireylerde ise son kaburga kemiği ile krista iliakanın en üst noktası ile orta nokta belirlenmiş ve ölçüm bu noktadan alınmıştır. Ölçüm alınırken bireyler ayakta dik bir şekilde ve bel çevresinde herhangi bir kıyafet olmadan alınmıştır. Ölçümler şerit metre ile alınmıştır. Ölçümlerde şerit metreye fazla baskı yapmadan deri ile temas halinde olmasına dikkat edilmiştir. Ölçüm alındıktan sonra araştırma formuna milimetrik olarak kaydedilmiştir (Martin, 1957; Tanner vd., 1969; Weiner ve Lourie, 1969).

Kalça Çevresi: Ölçü şerit metre ile alınmıştır. Birey ayakta ve dik bir konumda iken araştırmacı bireyin önünde femurlarının trochan terion noktalarının deri üzerinde denk gelen kısmından şerit metreyi yere paralel bir konumda tutarak ölçü almıştır. Şerit metre yere paralel bir durumdayken ve gerdirilerek ölçü alınmıştır. Alınan ölçü milimetrik olarak kaydedilmiştir. Bu ölçüm aynı zamanda kalçanın en çıkıntılı noktaları arasından geçmektedir (Martin, 1957; Tanner vd., 1969; Weiner ve Lourie, 1969). Beden kitle indeksinin değerlendirilmesinde Dünya Sağlık Örgütünün belirlediği referans değerleri kulanılmıştır. Bu değerler; BKİ $<18.50 \mathrm{~kg} / \mathrm{m}^{2}$ zayıf, $18.50-24.99 \mathrm{~kg} / \mathrm{m}^{2}$ normal, $30.00 \mathrm{~kg} / \mathrm{m}^{2}$ olması durumunda obezite olarak değerlendirilmiștir. Bel çevresi ve bel kalça oranı ölçümlerinin değerlendirilmesinde de Dünya Sağlık Örgütü'nün belirlediği referans değerleri kullanılmıştır. Buna göre bel çevresinin kadınlarda $80 \mathrm{~cm}$, erkeklerde $94 \mathrm{~cm}$ 'den fazla olması riskli olarak, kadınlarda $88 \mathrm{~cm}$ ve erkeklerde $102 \mathrm{~cm}$ ve üzeri ise obez olarak değerlendirilmiştir. Bel kalça 
oranında ise kadınlarda 0.85 , erkeklerde 0.90 ve üzeri olması obez olarak değerlendirilmiştir (WHO, 2008).

\section{Verilerin Analizi}

Elde edilen veriler Statistical Package for the Social Sciences (SPSS) v.16 programina aktarılmış, ortalama değerler, standart sapma ve yüzdelik oranlar ortaya konmuştur. Bununla birlikte değişkenlerin aralarındaki farkı anlamak için bağımsız örneklem t testi yapılmıştır. Değişkenler arasında korelasyon düzeyinin belirlenmesi için ise korelasyon analizi yapılmıştır. Tüm istatistiklerde $\mathrm{p}<0.05$ anlamlı olarak kabul edilmiştir.

\section{Bulgular}

Tablo 1

Örnekleme Ait Antropometrik Değerler

\begin{tabular}{|c|c|c|c|c|c|}
\hline & \multicolumn{2}{|c|}{ KADIN (n:201) } & \multicolumn{2}{|c|}{ ERKEK (n:205) } & \multirow{2}{*}{$\begin{array}{c}\mathrm{P} \text { değer } \\
\text { Sig. (2- } \\
\text { tailed) }\end{array}$} \\
\hline & ORTALAMA & $\begin{array}{l}\text { STANDART } \\
\text { SAPMA }\end{array}$ & ORTALAMA & $\begin{array}{l}\text { STANDART } \\
\text { SAPMA }\end{array}$ & \\
\hline Ağırlık (kg) & 58.51 & 9.46 & 73.85 & 11.06 & $0.00^{*}$ \\
\hline Boy $(\mathrm{mm})$ & 1604.0 & 56.8 & 1753.1 & 62.1 & $0.00^{*}$ \\
\hline Bel Çevresi (cm) & 69.25 & 7.07 & 80.91 & 8.69 & $0.00 *$ \\
\hline Kalça Çevresi (cm) & 95.31 & 7.67 & 99.11 & 7.13 & $0.00^{*}$ \\
\hline BKİ $\left(\mathrm{kg} / \mathrm{m}^{2}\right)$ & 22.78 & 3.62 & 23.97 & 3.32 & $0.01 *$ \\
\hline $\begin{array}{l}\text { BKO (bel çevresi/kalça } \\
\text { çevresi) }\end{array}$ & 0.72 & 0.04 & 0.81 & 0.04 & $0.00 *$ \\
\hline
\end{tabular}

Örnekleme ait antropometrik değerlerin ortalaması tablo 1'de verilmiştir. Alınan bütün antropometrik değerlerde erkek bireylerin daha yüksek ortalamalara sahip olduğu ortaya çıkmış ve cinsiyetler arası anlamlı farka rastlanılmıştır $(\mathrm{p}<0.05)$.

Tablo 2

Beden Kitle İndeksi, Bel Çevresi, Bel Kalça Oranı Yöntemlerine Göre Obezite Oranları

\begin{tabular}{llllll}
\hline & $\begin{array}{c}\text { Beden Kitle İndeksi } \\
\%\end{array}$ & $\begin{array}{c}\text { Bel Çevresi } \\
\%\end{array}$ & \multicolumn{2}{c}{$\begin{array}{c}\text { Bel Kalça Oran } \\
\%\end{array}$} & \\
\cline { 2 - 5 } & & Obez & & Obez & \multicolumn{2}{c}{ Obez } & Toplam (n) \\
\cline { 2 - 5 } Kadın & 4.5 & 3 & 1 & 201 \\
Erkek & 6.4 & 2.4 & 4.4 & 205 \\
Toplam & 5.4 & 2.7 & 2.7 & 406 \\
\hline
\end{tabular}

Kullanılan üç yöntem ile ortaya koyulan obezite oranlarına bakıldığında her iki cinsiyette de beden kitle indeksinin, diğer yöntemlerden fazla sonuç ortaya koyduğu görülmektedir. Kadınlar üzerinde en düşük obezite oranını veren yöntem bel-kalça oranı iken erkekler üzerinde en düşük obezite oranı bel çevresi ölçümünden elde edilmiştir.

Tablo 3

Kullanılan Yöntemlerin İstatistiksel Olarak Karșılaștırılması

\begin{tabular}{lcc}
\hline & Korelasyon Katsayısı & Anlamlılık Düzeyi (p değeri) \\
\cline { 2 - 3 } Beden Kitle İndeksi-Bel Çevresi & .599 & $.000^{*}$ \\
Beden Kitle İndeksi-Bel Kalça Oranı & .175 & $.000^{*}$ \\
Bel Çevresi-Bel Kalça Oranı & .380 & $.000^{*}$ \\
\hline *p $<0.05$ anlamlı &
\end{tabular}


Kullanılan üç yöntem kendi aralarında istatistiksel olarak karşılaştırıldığında aralarında anlamlı bir fark bulunmuştur $(\mathrm{p}<0.05)$.

Tablo 4'te yapılan çalışmanın benzer çalışmalar ile boy ortalaması, ağırlık ortalaması, beden kitle indeksi ortalaması açısından karşılaştırılmasına yer verilmiştir.

Tablo 4

Araştırmadan Elde Edilen Antropometrik Ölçümlerin Diğer Çalışmalar ile Karşılaş̧tırılması

\begin{tabular}{|c|c|c|c|c|c|c|c|}
\hline \multirow[b]{2}{*}{ Yil } & \multirow[b]{2}{*}{ Araştırmacı } & \multicolumn{2}{|c|}{$\begin{array}{c}\text { Boy } \\
\text { Ortalamas1 } \\
\end{array}$} & \multicolumn{2}{|c|}{ Ağırlık Ortalaması } & \multicolumn{2}{|c|}{$\begin{array}{c}\text { Beden Kitle İndeksi } \\
\text { Ortalaması }\end{array}$} \\
\hline & & Kadın & Erkek & Kadın & Erkek & Kadın & Erkek \\
\hline 2003 & $\begin{array}{l}\text { Güney, Özgen, } \\
\text { Saraç, Y1lmaz ve } \\
\text { Kabalak }\end{array}$ & \multicolumn{2}{|c|}{159.6} & \multicolumn{2}{|c|}{90.9} & \multicolumn{2}{|c|}{35.5} \\
\hline 2005 & Şanlier & 163.5 & 175.7 & 56.3 & 69.7 & 21.0 & 22.6 \\
\hline 2007 & $\begin{array}{l}\text { Başıbüyük } \\
\text { ve Akın }\end{array}$ & 154.2 & 167.9 & 72.08 & 78.94 & 30.43 & 27.99 \\
\hline 2012 & Durgun & 160.7 & 175.2 & 68.4 & 81.5 & 26.6 & 26.5 \\
\hline 2013 & Murathan & 164.3 & 176.6 & 63.3 & 72.3 & 24.8 & 23.4 \\
\hline 2016 & Özütürker & 161.4 & 175.9 & 57.5 & 71.6 & 21.9 & 23.1 \\
\hline 2016 & $\begin{array}{l}\text { Sözmen, Ünal, } \\
\text { Sakarya, Dinç, } \\
\text { Yardım, } \\
\text { Keskinkılınç ve } \\
\text { Ergör }\end{array}$ & & & & & 29.37 & 26.86 \\
\hline 2017 & Büyükakın & - & & & & 26.42 & 26.49 \\
\hline 2017 & $\begin{array}{l}\text { Çatırtan } \\
\text { ve Bakır }\end{array}$ & & & & & 23.01 & 25.26 \\
\hline 2019 & $\mathrm{Bu}$ Araştırma & 160.4 & 175.3 & 58.51 & 73.85 & 22.78 & 23.97 \\
\hline 2007 & $\begin{array}{l}\text { Novotny, } \\
\text { Nabokov, Derauf, } \\
\text { Grove ve } \\
\text { Vijayadeva }\end{array}$ & 166.6 & & 87.2 & & 31.4 & \\
\hline 2008 & Freiberg & 164.7 & 177.5 & 66.7 & 84.7 & 24.5 & 26.9 \\
\hline 2019 & $\begin{array}{l}\text { Chen, Yang, } \\
\text { Jiang, Liang, } \\
\text { Wang ve Lu }\end{array}$ & & & & & & \\
\hline
\end{tabular}

Tablo 4'te görüldüğü üzere elde edilen boy ortalaması, ağırlık ortalaması, beden kitle indeksi ortalaması diğer çalışamalar ile karşılaştırıldığında genel anlamda daha düşük değerlere sahip olduğu ortaya konmuştur.

Tablo 5'te yapılan çalışmanın benzer çalışmalar ile bel çevresi ortalaması, kalça çevresi ortalaması, bel kalça oranı ortalaması açısından karşılaştırılmasına yer verilmiştir. 
Tablo 5

Araştırmadan Elde Edilen Antropometrik Ölçümlerin Diğer Çalışmalar ile Karşılaş̧tırılması

\begin{tabular}{|c|c|c|c|c|c|c|c|}
\hline \multirow[b]{2}{*}{ Yil } & \multirow[b]{2}{*}{ Araştırmacı } & \multicolumn{2}{|c|}{$\begin{array}{l}\text { Bel Çevresi } \\
\text { Ortalamas1 }\end{array}$} & \multicolumn{2}{|c|}{$\begin{array}{c}\text { Kalça Çevresi } \\
\text { Ortalaması }\end{array}$} & \multicolumn{2}{|c|}{$\begin{array}{c}\text { Bel-Kalça Oranı } \\
\text { Ortalaması }\end{array}$} \\
\hline & & Kadın & Erkek & Kadın & Erkek & Kadın & Erkek \\
\hline 2003 & $\begin{array}{l}\text { Güney, Özgen, } \\
\text { Saraç, Yılmaz ve } \\
\text { Kabalak }\end{array}$ & \multicolumn{2}{|c|}{97.3} & \multicolumn{2}{|c|}{120.9} & & \\
\hline 2005 & Şanlıer & 71.3 & 78.6 & & & 0.74 & 0.81 \\
\hline 2007 & $\begin{array}{l}\text { Başıbüyük } \\
\text { ve Akın }\end{array}$ & \multicolumn{2}{|c|}{-} & \multicolumn{2}{|c|}{-} & 0.83 & 0.93 \\
\hline 2012 & Durgun & 86.7 & 95.9 & 105.6 & 104.8 & 0.81 & 0.91 \\
\hline 2013 & Murathan & 61.2 & 83.8 & 103.1 & 101.4 & 0.80 & 0.90 \\
\hline 2016 & Özütürker & & & & & 0.70 & 0.81 \\
\hline 2016 & $\begin{array}{l}\text { Sözmen, Ünal, } \\
\text { Sakarya, Dinç, } \\
\text { Yardım, } \\
\text { Keskinkılınç ve } \\
\text { Ergör }\end{array}$ & 91.20 & 94.79 & & & 0.85 & 0.95 \\
\hline 2017 & Büyükakın & 89.24 & 96.93 & 107.23 & 104.87 & 0.82 & 0.92 \\
\hline 2017 & $\begin{array}{l}\text { Çatırtan } \\
\text { ve Bakır }\end{array}$ & 76.7 & 89.28 & 76.7 & 77.63 & & \\
\hline 2019 & $\mathrm{Bu}$ Araştırma & 69.25 & 80.91 & 95.31 & 99.11 & 0.72 & 0.81 \\
\hline 2007 & $\begin{array}{l}\text { Novotny, } \\
\text { Nabokov, Derauf, } \\
\text { Grove ve } \\
\text { Vijayadeva }\end{array}$ & & & & & & \\
\hline 2008 & Freiberg & & & & & & \\
\hline 2019 & $\begin{array}{l}\text { Chen, Yang, } \\
\text { Jiang, Liang, } \\
\text { Wang ve Lu }\end{array}$ & & & & & & \\
\hline
\end{tabular}

Tablo 5'te görüleceği üzere benzer çalışmalar ile bel çevresi ortalaması, kalça çevresi ortalaması, bel kalça oranı ortalaması açısından karşılaştırıldığında değerlerin büyük ölçüde diğer çalışmalardan düşük seviyelerde olduğu gözlemlenmektedir.

\section{Sonuç, Tartışma ve Öneriler}

Fazla kiloluluk ve obezite, her yaş grubunda ve cinsiyette önemli bir sağlık problemi olarak karşımıza çıkmaktadır. En yalın haliyle vücutta aşırı yağ birikmesi olarak tanımlanan obezite birçok hastalık için risk faktörüdür. Türkiye Endokrinoloji ve Metabolizma Derneği'nin 2018 yılında yayınlanan raporuna göre Dünya Sağlık Örgütü her yıl obezite ve obezitenin neden olduğu hastalıklar ile ilişkili olarak ortalama 3 milyon insanın hayatını kaybettiğini ve 2016 yılında Türkiye'deki obez birey sayısını 16.092.644 olarak bildirmiştir. Bu rakam ülkenin \%29.5'ine denk gelmektedir. Ülkemizde de obezite oranları hızlı bir şekilde artmaktadır. Öyle ki Türkiye, Avrupa'da obezitenin en çok görüldüğü ülke konumundadır (Türkiye Endokrinoloji ve Metabolizma Derneği, 2018).

Obezite genel hastalık oranlarının yanı sıra ölüm oranlarında da artış sağlanmasına sebep olan yaygın bir halk sağlı̆̆ problemidir. Genellikle kadınlarda ve kentsel ortamlarda daha yaygın gözlemlenmektedir. Popülasyonlar üzerinde obezite taraması yapılırken genellikle antropometrik 
yöntemler tercih edilmektedir. Antropometrik yöntemlerin en belirgin avantajları taşınabilir, ucuz ve saha çalışmalarında faydalı olmalarıdır. Ağırlığı boy ile ilişkilendiren bedenkitle indeksi, vücut boyutunun en yaygın kullanılan aynı zamanda en basit ölçüsüdür ve bir popülasyondaki obezite prevalansını tahmin etmek için sıklıkla kullanılır (Akpınar vd., 2007). Ancak yağ oranını ortaya koymaması, kas kitlesi fazla olan veya su tutan vücutta bireylerin beden kitle indeksi değerinin fazla çıkması pek çok eleştiriye maruz kalmıştır. Bu nedenlerden ötürü beden kitle indeksine alternatif yöntemler aranmaktadır. Bu noktada çevre ölçümleri bireyin yağlılık durumu ile ilgili direkt bilgi verdiğinden tercih sebebidir. Bu araştırmada da beden kitle indeksi ve bel çevresi, bel kalça oranı ölçümlerinin birbirlerine benzer veya farklı sonuçlar verip vermediği ortaya konulmaktadır.

Tablo 4 ve 5'te örnekleme ait antropometrik değerlerin ortalaması verilmiştir. Bu değerlerin yapılan benzer çalışmaların örneklemi ile kıyaslandığında nispeten daha düşük olduğu görülmektedir.

Yapılan araştırma sonucunda elde edilen bulgular göstermektedir ki beden kitle indeksine göre obez birey oranı kadınlarda \%4.5, erkeklerde \%6.4, toplamda \%5.4'tür. Ergün ve Erten'in 2004'te Ankara'da yaptığı çalışmada kadınlarda obez birey oranını $\% 0.5$, erkeklerde $\% 2.5$, toplamda $\% 1.5$ olarak bulmuşlardır (Ergün ve Erten, 2004). Bu sonuçlar her iki cinsiyette de elde edilen bulgulardan daha düşük değerler göstermektedir. Akpınar vd.'nin 2007 yılında Adana'da yetişkin bireyler üzerinde yaptığ çalışmada beden kitle indeksi değerine göre obez birey oranı kadınlarda \%37.6, erkeklerde \%48.1, toplamda \%28.4'tür (Akpınar vd., 2007). Bu değerlerin yapılan çalışmadan oldukça yüksek olduğu görülmüsstür. 2014 yılında Bektaş ve arkadaşlarının çalışmasında kadınlarda beden kitle indeksine göre obez birey oranı \%1.5, erkeklerde obez birey oranı \%6'dır (Bektaş, Gültekin, Akın ve Önal, 2014). Bu bilgilere göre, kadınlarda obez birey oranı yapılan çalışmadan daha düşük bir değer gösterirken erkeklerdeki obez birey oranı benzerlik göstermektedir.

Obeziteye bağlı sağlık riskleri genel vücut yağlanmasının yanı sıra, özellikle karın bölgesinde yağın dağılımı ile ilgilidir. Karın içi yağ dokusu obeziteye bağlı birçok hastalık riskinde genel vücut yağından daha fazla önem taşımaktadır (Heyward ve Stolarczyk, 1969). Bu nedenle bel çevresi ölçümü ile bel kalça oranı 1980'li yıllardan bu yana bölgesel olarak bulunan yağın ve obezite ile ilişkili diğer kronik sorunların ortaya çıkma riskiyle olan ilişkisininbilimsel olarak tanınmasını sağlayan öncü çalışmalarda kullanılmıştır. Viseral (karın içi) veya bölgesel yağın en doğru ölçümü bilgisayarlı tomografi (BT) ve manyetik rezonans görüntüleme (MR) olarak bilinmektedir. Ancak bu yöntemler pahalı ve pratik değildir. Bel çevresi bu nedenle klinik teşhiste en pratik yöntemdir. Bel çevresi ölçümü, aynı zamanda kilo kaybını takip etmek için de en iyi araçtır. Bireyler fiziksel olarak aktif hale geldiğinde bel çevresi ölçümü daha değerlidir. Fiziksel aktivite kas kitlesinin kaybını yavaşlatır böylece yağlar mobilize olurken birey yavaşca kilo kaybeder. Bel çevresindeki değişiklikler birey kilo kaybetmese dahi yă̆ oranının azalması ile ilgili değişiklikleri anlamaya yardımcı olur (Bray, 2004).

Araştırma kapsamında bel çevresine göre obez birey oranı kadınlarda \%3, erkeklerde \%2.4 olarak bulunmuştur. Ergün ve Erten'in 2004 yılında yaptığı çalışmada kadınlarda bel çevresine göre obezite oran1 \%3.1, erkeklerde ise \%1.4'dir (Ergün ve Erten, 2004). Bu çalışma Ergün ve Erten'in çalışması ile karşılaştırıldığında, kadınlarda görülen obezite oranı benzer seviyede iken erkeklerde görülen obezite oranı düşük bir değer göstermektedir. Akpınar vd.'nin2007 yılında yaptığı çalışmada bel çevresi ölçümüne göre obez birey oranı kadınlarda $\% 51.7$, erkeklerde $\% 11.7$ olarak bulmuşlardır. (Akpınar vd., 2007). Bu çalışma ile karşılaştırıldığında, Akpınar vd'nin elde ettiği sonuçların oldukça yüksek değerler ortaya koyduğu görülmektedir.

Bel kalça oranına göre obez birey oranı kadınlarda \%1, erkeklerde \%4.4 olarak bulunmuştur. Akpınar vd.'nin 2007 y1lında yaptığı çalışmada elde ettiği bulgular bu çalışmadan oldukça fazladır (kadınlarda \%65.5, erkeklerde \%17.6). Cinsiyetler açısından beden kitle indeksi, bel çevresi ölçümü, bel kalça oranına göre obez birey sayıları karşılaştırıldığında, beden kitle indeksi ve bel kalça oranına göre cinsiyetler arasında anlamlı bir fark bulunmaktadır $(\mathrm{p}<0.05)$. Ancak bel çevresi oranına göre karşılaştırma yapıldığında anlamlı bir farka rastlanılmamıştır ( $p>0.05)$. Her iki cinsiyette bel çevresine göre obez birey sayısı benzerlik göstermektedir. Akpınar vd.'nin aktardığına göre fazla kilolu olma 
sıklığı erkeklerde, obezite ise kadın bireylerde daha fazladır (Akpınar vd., 2007). Fakat bu çalışmadan elde edilen bulgulara göre beden kitle indeksi ve bel kalça oranına göre erkek obez birey sayısı fazla, bel çevresine göre ise kadın obez birey sayısı fazladır.

Üç yöntemin istatistiksel olarak karşılaştırılması sonucu aralarındaki fark anlamlı bulunmuştur $(\mathrm{p}<0.05)$. Üç yöntemin birbirinden farklı sonuçlar ortaya koyması araştırmanın problem ve amacını destekler niteliktedir. Beden kitle indeksine göre kadınlarda obez birey oran $1 \% 4.5$, bel çevresine göre $\% 3$, bel kalça oranına göre \%1 bulunmuştur. Bel kalça oranının kadınlar üzerinde uygulanmasını destekleyen araştırmalar olsa da araştırma sonucunda kadınlarda en düşük sonucu bel kalça oranı vermiştir. Her iki yöntemde obez olup bel kalça oranı sonucuna göre obez olmayan bireylerin bulunması bel kalça oranının kadınlar için uygun olup olmamasını sorgulamayı gerekli kılmaktadır.

Akpınar vd. çalışmalarında bel kalça oranını çeşitli risk faktörleri değerlendirmede en yararlı obezite ölçüsü olarak tanımlamaktadır (Akpınar vd., 2007). Ancak literatürde şişmanlığın artması ile birlikte bel kalça oranının doğruluğunun azalabileceği bilgisi yer almaktadır (Heyward ve Stolarczyk, 1996). Buna ek olarak bireylerin orantılı bir şekilde kilo alması aynı anda hem bel çevresini hem de kalça çevresini artıracağından bel kalça oranı değeri değişmese bile bireyin kilo oranı ve yağ oranı artı̧̧ gösterebilir. Zayıf veya obez olmayan ama bel çevresi-kalça çevresi ölçüleri birbirine yakın olan bireylerde bel kalça oranı değeri yanıltıcı olabilmektedir. Popülasyonlar üzerinde çalışma yaparken bu durum yanıltıcı sonuçlara ulaşmaya neden olabilir.

Ho vd. beden kitle indeksi ve bel çevresi ölçümünün erkekler için en etkili yöntem olduğunu, kadınlar için ise bel çevresi ve bel kalça oranı yöntemlerinin daha etkili olduğu öne sürmüştür (Ho, Chen, Woo, Leung, Lam ve Janus., 2001). Bu araştırmada ise elde edilen bulgulara bakıldığında bel kalça oranına göre kadınlarda en az obezite düzeyi görülmektedir. Bu sonuç Ho vd.'nin elde ettiği bulgu ile zıtlık göstermektedir. Yine bu araştırmadan elde edilen bulgulara bakıldığında beden kitle indeksi ve bel çevresi değerlerinin erkek bireylerde oldukça farklı sonuçlar ortaya koyduğu görülmektedir.

Obezite teşhis edilirken birden fazla yöntemden yararlanmanın daha doğru sonuç vereceği düşünülmektedir. $\mathrm{Bu}$ araştırmada kullanılan yöntemler karşılaştırıldığında kadınlarda beden kitle indeksi, bel çevresi metotlarından yola çıkarak obezite teşhisi yapılabileceği, ancak bel kalça oranı değerinden bir teşhiste bulunmanın çok doğru olmayacağı görülmektedir. Erkeklerde bel kalça oranının yalnızca abdominal obezite oranını ortaya koyduğu, genel obezite oranı hakkında doğru bir bilgi vermediği görülmektedir. $\mathrm{Bu}$ nedenle beden kitle indeksi ve bel çevresi metotlarından yararlanılarak obezite teşhisinin yapılmasının en doğru sonuç olacağı düşünülmektedir. Türkiye Endokrinoloji ve Metabolizma Derneği 2018 raporunda da araştırmamız ile benzer olarak obezite tanısında beden kitle indeksi ve bel çevresi ölçümlerinin birlikte kullanılmasını önermektedir (Türkiye Endokrinoloji ve Metabolizma Derneği, 2018). Seidell 2010 yılında yayımlanan çalışması ile bel çevresinin önemini vurgulayarak bel çevresi ölçümünü tek başına beden kitle indeksi ve bel kalça oranının yerini alabilecek önemli bir faktör olarak belirtmiştir (Seidell, 2010).

Elde edilen bulgular sonucunda obezite teşhisinde birden fazla yöntemin bir arada değerlendirilmesi özellikle bel çevresi ölçümü gibi direkt olarak yağ oranı hakkında bilgi veren ölçümlerin göz ardı edilmemesi önerilmektedir. Beden kitle indeksi ile elde edilen veri mutlaka bel çevresi ölçümü ile desteklenmelidir. Kadın ve erkek bireyler arasındaki bölgesel yağlanma farklılıklarını düşünerek yapılacak çalışmalarda cinsiyetlere özgü farklılıklar göz önünde bulundurularak en doğru ölçüm tekniğinin kullanılması önerilmektedir. Bir yöntemden yola çıkarak bireylere obezite teşhisi koymanın doğru sonuçlar vermeyeceği düşünülmektedir. Obezite teşhisinde hangi yöntemin kullanılması gerektiği uzun zamandır süregelen bir tartışma konusu olduğundan veri çeşitliliğini arttırmak adına benzer çalışmaların farklı örneklem gruplarında yapılması önerilmektedir.

\section{Yazarların Katkı Oranı}

Bu makaleye birinci yazarın \%60, ikinci yazarın \%40 oraninda katkısı vardır. 


\section{Çıkar Çatışması}

Bu çalışmada çıkar çatışması oluşturacak bir husus yoktur.

Açıklamalar: Bu çalışma Kırşehir Ahi Evran Üniversitesi, Sosyal Bilimler Enstitüsü 580847 no’lu "Obezitenin Belirlenmesinde Kullanılan Beden Kitle İndeksi, Bel Çevresi, Bel-Kalça Oranı Metotlarının Karşılaştırılması" konulu tezden üretilmiştir.

\section{Kaynaklar}

Akpınar, E. Bashan, İ. Bozdemir, N. and Saatci E. (2007). Which is the best anthropometric technique to identify obesity: Body mass index, waist circumference or waist-hip ratio? Collegium Antropologicum, 31(2), 387-393. https://doi.org/10.1111/j.1365-2796.2003.01229.x

Başıüyük, Ö.G. ve Akın, G. (2007). Sivas il merkezinde yetişkin kadın ve erkeklerde obezite değerleri. Turkish Studies, 2(4), 1239-1261. http://dx.doi.org/10.7827/TurkishStudies.233

Bektaş, Y. Gültekin, T. Akın, G. ve Önal, S. (2014). Obezitenin değerlendirilmesinde beden kütle indeksi ve biyoelektrik empedans metotlarının etkinliğinin karşılaştırılması. Ankara Üniversitesi Dil ve Tarih-Coğrafya Fakültesi Antropoloji Dergisi, 28, 67-86. https://doi.org/10.1501/antro_0000000303

Bellisari, A. and Roche, A.F. (2005). Anthropometry and ultrasound. In Heymsfield, S.B. Lohman, T.G. Wang, Z. Going, S.B. (Eds.). Human body composition (ss.109-128). United States of America: Human Kinetics.

Berghöfer, A. Pischon, T. Reinhold, T. Apovian, C.M. Sharma, M.A. and Willich, S.N. (2008). Obesity prevalence from a european perspective: A systematic review. BMC Public Health. 8(200), 1-10. https://doi.org/10.1186/1471-2458-8-200

Büyükakın, B. (2017). Erişkinlerde obezite tanı ve izleminde kullanılan iki farkl yöntemin uyumunun değerlendirilmesi. Uzmanlık Tezi. Pamukkale Üniversitesi, Denizli.

Bray, G. (2004). Classification and evaluation of the overweight patient. Bray, G. Bouchard, C. (Eds), Handbook of obesity (ss. 1-32). New York: Marcel Dekker, Inc.

Chen, Y. Yang, Y. Jiang, H. Liang, X. Wang, Y. and Lu, W. (2019). Associations of bmi and waist circumference with all-cause mortality: A 22-year cohort study. Obesity. 27(4), 662-669. https://doi.org/10.1002/oby.22423

Çatırtan, H. ve Bakır, B.O. (2018). Comparison of sleep quality, waist circumference and body mass Index among shift and non-shift workers. Journal of Turkish Sleep Medicine. 5(2), 40-45. DOI: $10.4274 /$ jtsm.33043

Durgun, G.A. (2012). Bursa ilinde obezite sıklı̆̆l ve ilişkili faktörler. Uzmanlık Tezi. Uludă̆ Üniversitesi, Bursa.

Ergün, A. ve Erten, S.F. (2004). Öğrencilerde vücut kitle indeksi ve bel çevresideğerlerinin incelenmesi. Ankara Üniversitesi Tip Fakültesi Mecmuast. 2(57), 57-61. https://doi.org/10.1501/Tipfak_0000000102

Freiberg, S.M. Michael, J. Pencina, M.J. D’Agostino, R.B. Lanier, K. Wilson, P.W.F. and Vasan, S.R. (2008). BMI vs. waist circumference for 1dentifying vascular risk. Obesity. 16(2), 463-469. https://doi.org/10.1038/oby.2007.75 
Güney, E. Özgen, A.G. Saraç, F. Yılmaz, C. ve Kabalak, T. (2003). Biyoelektrik impedans yöntemi ile obezite tanısında kullanılan diğer yöntemlerin karşılaştırılması. Adnan Menderes Üniversitesi Tip Fakültesi Dergisi. 4(2), 15-18.

Heyward, V.H. and Stolarczyk, L.M. (1996). Applied body composition assesment. United States of America: Human Kinetics.

Ho, S. Chen, Y. Woo, J. Leung, S. Lam, T. and Janus, E. (2001). Association between simple anthropometric indices and cardiovascular risk factors. International Journal of Obesity and Related Metabolic Disorders. 25(11), 1689-1697. https://dx.doi.org/10.22122\%2Farya.v15i1.1307

Martin, R. (1957). Lehrbuch der antropologie. Saller, K. (Ed.). (3th ed.). Stuttgart: G. Fisher Verlag.

Murathan, F. (2013). Üniversite ögrencilerinde obezite slklığl, fiziksel aktivite düzeyi ve sağhlkll yaşam biçimi davranışlarının incelenmesi. Doktora Tezi. Furat Üniversitesi Sağlı Bilimleri Enstitüsü, Elazı̆g.

Novotny, R. Nabokov, V. Derauf, C. Grove, J. and Vijayadeva, V. (2007). BMI and waist circumference as indicators of health among samoan women. Obesity. 8(15), 1913-1917. https://doi.org/10.1038/oby.2007.227

Özütürker, S. (2016). Üniversite ögrrencilerinde beslenme durumları ve antropometrik profillerinin belirlenmesi: Erzincan örneği. Doktora Tezi. Ankara Üniversitesi Sosyal Bilimler Enstitüsü, Ankara.

Seidell, J.C. (2010). Waist circumference and waist/hip ratio in relation to all-cause mortality, cancer and sleep apnea. European Journal of Clinical Nutrition. 64(1), 35-41. https://doi.org/10.1038/ejen.2009.71

Sözmen, K. Ünal, B. Sakarya, S. Dinç, G. Yardım, N. Keskinkılınç, B. ve Ergör, G. (2016). Türkiye'de antropometrik ölçüm yöntemlerinin kardiyovasküler hastalık riski ile ilişkisi. Dicle Üniversitesi Tip Fakültesi Dergisi. 43(1), 99-106. doi: 10.5798/diclemedj.0921.2016.01.0646

Sturm, R. (2002). The effects of obesity, smoking and drinking on medical problems and costs. Health Affairs. 21(2), 245-253. https://doi.org/10.1377/hlthaff.21.2.245

Şanlıer, N. (2005). Gençlerde biyokimyasal bulgular, antropometrik ölçümler, vücut bileşimi, beslenme ve fiziksel aktivite durumlarının değerlendirilmesi. Gazi Üniversitesi Gazi Eğitim Fakültesi Dergisi. 3(25), 47-73. http://www.gefad.gazi.edu.tr/tr/issue/6755/90826

Tanner, JM. Hiernaux, J. and Jarman, S. (1969). Growth and physique studies. Weiner, JS. Lourie, JA. (Eds.). Human biology: A guide to field methods; (I.B.P. Handbook No:9) (ss.1-76). Oxford: Blackwell Scientificp.

Turan, İ. (2017). Diyarbakır ili kayapınar ilçesi gaziler 1 nolu aile sağlı̆̆ı merkezi'ne kayıtlı 19 yaş ve üzeri kişilerde obezite siklı̆̆l, risk faktörleri ve obezite eğitimi sonrası yaşam tarzı değişikliklerinin incelenmesi. Uzmanlık Tezi. Dicle Üniversitesi, Diyarbakır.

Türkiye Endokrinoloji ve Metabolizma Derneği. (2018). Obezite tanı ve tedavi klavuzu. Ankara: BAYT Bilimsel Araştırmalar Basın Yayın ve Tanıtım. 
Ünal, G. (2010). Yetişkin kadınlarda yaşam koşullarının antropometrik ölçümler ve obezite ile ilişkisi. Yüksek Lisans Tezi. Ankara Üniversitesi, Ankara.

Weiner, JS. and Lourie, JA. (Eds.). (1969). Human biology: A guide to field methods; (I.B.P. Handbook no:9). Oxford: Blackwell Scientific.

World Health Organization. (2008). Waist circumference and waist-hip ratio: Report of a WHO expert consultation. Geneva: WHO. 


\section{Extended Abstract}

\section{Introduction}

Obesity is a metabolic disease that is known as overweight among the public. It causes many diseases if precautions are not taken, and can lead to deaths due to these diseases. The World Health Organization explains the average number of deaths due to obesity every year as 3 million. These numbers increase day by day in Turkey. There are many methods used to diagnose obesity, but such an increase in cases requires the methods to be used in the diagnosis of obesity to be practical and reliable. Within the scope of this research, determination of obesity prevalence by anthropometric measurements taken from 406 individuals at Kırşehir Ahi Evran University, waist circumference and waist hip ratio methods, and which method used in determining obesity have different results, which method is preferred in the diagnosis of obesity. The main purpose of the research is to compare how these three methods yield results on the same population by comparing these three methods among themselves, since they create question marks about the future

\section{Method}

Data subject to the research The meeting of the Social and Humanities Scientific Research and Publication Ethics Committee of Kırşehir Ahi Evran University dated 23.11.2018 with the decision number 2018-23 / 07, this research consists of 201 women and 206 men over the age of 18 at various faculties of Kırşehir Ahi Evran University between 2018 and 2019. Within the scope of the research, anthropometric measures taken to determine the levels of obesity and obesity in individuals were taken by cross-sectional method, in line with the standards stipulated by Anthropometric Standardization Reference Manual (ASRM) and techniques envisaged by Martin and Saller (1957). In addition, the recommendations of the International Biological Program (IBP) have been taken into consideration. The data obtained were transferred to the Statistical Package for the Social Sciences (SPSS) v.16 program. In all statistics, $\mathrm{p}<0.05$ was considered significant.

\section{Results}

The average weight in women was $58.51 \mathrm{~kg}$, height average was $1604.0 \mathrm{~mm}$, waist circumference was $69.25 \mathrm{~cm}$, hip circumference was $95.31 \mathrm{~cm}$, body mass index was $22.78 \mathrm{~kg} / \mathrm{m} 2$ and waist hip ratio was 0.72 . In men, the average weight was $73.85 \mathrm{~kg}$, the average height was 1753.1 $\mathrm{mm}$, the waist circumference was $80.91 \mathrm{~cm}$, the hip circumference was $99.11 \mathrm{~cm}$, the body mass index was $23.97 \mathrm{~kg} / \mathrm{m} 2$ and the waist hip ratio was 0.81 . According to body mass index, the rate of obese individuals in women is $4.5 \%, 6.4 \%$ in men and $5.4 \%$ in total. The proportion of obese individuals according to waist circumference is $3 \%$ in women, $2.4 \%$ in men and $2.7 \%$ in total. The ratio of obese individuals is $1 \%$ in females, $4.4 \%$ in males and $2.7 \%$ in total, according to the waist to hip ratio.

\section{Discussion}

The anthropometric findings and similar studies obtained are given in table 4 . These findings seem to be relatively lower compared to the sample of similar studies. Height length, weight, waist circumference, hip circumference measurements, body mass index and waist hip ratio parameters were statistically compared between men and women and a significant difference was found $(\mathrm{p}<0.05)$. When the obesity rates revealed by the three methods used are analyzed, it is seen that the body mass index in both sexes shows more results than the other methods. While the method that gives the lowest obesity rate on women is waist-hip ratio, the lowest obesity rate on men was obtained by measuring waist circumference. When the three methods used were compared statistically, a significant difference was found between them $(\mathrm{p}<0.05)$. When the body mass index, waist circumference, waisthip ratio of obese individuals are compared in terms of gender, there is a significant difference between the sexes by body mass index and waist-hip ratio $(\mathrm{p}<0.05)$. However, no significant difference was found when comparing according to waist circumference ratio ( $p>0.05)$. In both sexes, the number of obese individuals is similar compared to the waist circumference. As a result of 
statistical comparison of the three methods, the difference between them was found significant $(\mathrm{p}<0.05)$. The fact that the three methods yield different results supports the problem and purpose of the research. Although there are studies supporting the application of waist to hip ratio, the lowest result in women has given the lowest hip result. In both methods, the presence of non-obese individuals according to the results of the waist to hip ratio makes it necessary to question whether the waist to hip ratio is suitable for women. Since individuals gaining weight in proportion would increase both waist circumference and hip circumference at the same time, the weight ratio and fat rate of the individual may increase even if the waist hip ratio value does not change. For individuals whose fit or non-obese but waist circumference-hip circumference measures close together, waist hip ratio value can be misleading. This can lead to misleading results when working on populations. It is thought that using more than one method will be more accurate when diagnosing obesity. When the methods used in this study are compared, it can be seen that obesity can be diagnosed in women based on body mass index, waist circumference methods, but it is not right to make a diagnosis based on but only waist hip ratio value. It appears that the ratio of waist to hip in men only demonstrates the rate of abdominal obesity and does not give accurate information about the overall rate of obesity. For this reason, it is thought that making the diagnosis of obesity by using body mass index and waist circumference methods will be the most accurate result. As a result of the findings, it is recommended to evaluate at least two methods in the diagnosis of obesity. Data obtained with body mass index should be supported by waist circumference measurement. Based on just one method, it is thought that diagnosing individuals with obesity will not yield accurate results. 